\title{
Arte, género y educación: diálogo en Brasil con Everson Melquiades, Vitória Amaral y Fabio Rodrigues
}

\author{
Ricard HUERTA. Universitat de València (España). ricard.huerta@uv.es
}

Esta entrevista ha sido posible gracias a la celebración en Brasil del "II Seminário Internacional Arte/Gênero/Ensino em tempos de conservadorismo". El Seminario tuvo lugar en el Centro de Artes de la URCA Universidad Regional do Cariri, ubicado en la ciudad de Crato (Ceará). Se trata de un evento único en Latinoamérica, por su especificidad. El formato del Seminario resulta muy atractivo y completo, ya que a lo largo de cinco días (del 12 al 16 de agosto de 2019) tienen lugar muchas actividades tanto académicas como de creación artística, lo cual permite asistir a conferencias plenarias, mesas redondas, sesiones de comunicaciones, pero también a piezas teatrales, espectáculos de danza, performances artísticas en diferentes lugares de la ciudad, exposiciones de artes visuales, y un sinfín de actividades más. Un programa extenso y variado en el que detectamos el buen hacer de Fabio Rodrigues y Renata Felinto, auténticos movilizadores de todo este engranaje universitario, una apuesta de la URCA en la que se han implicado diferentes grupos de investigación: NEPEA Núcleo de Estudos e Pesquisas em Estudos da Arte, GPEACC Grupo de Pesquisa Ensino da Arte em Contextos Contemporáneos, NZINGA Novos Ziriguiduns (Inter)Nacionais Guerados na Arte, OAC Grupo de Pesquisa Ocupaçoes Artísticas da Cidade. Hemos optado por reunir en este diálogo compartido a tres referentes del arte/educación del Brasil: Everson Melquiades, Vitória Amaral y Fabio Rodrigues. Se trata de tres figuras importantes, con trayectorias consolidadas, y que destacan por su implicación en temas de género, abordando la cuestión tanto desde los feminismos como desde la diversidad sexual. La entrevista fue realizada el jueves 15 de agosto de 2019. Ubicados en las instalaciones del Centro de Artes Reitora Maria Violeta Arraes de Alencar Gervaiseau, la conversación se inició a las cuatro de la tarde y duró más de tres horas, durante las cuales, además de contestar a las cuestiones planteadas, los participantes explicaron sus diferentes posicionamientos, valorando las distintas opciones, y sin perder de vista la situación tan complicada que vive actualmente Brasil, un país que es referencia mundial en educación artística. 


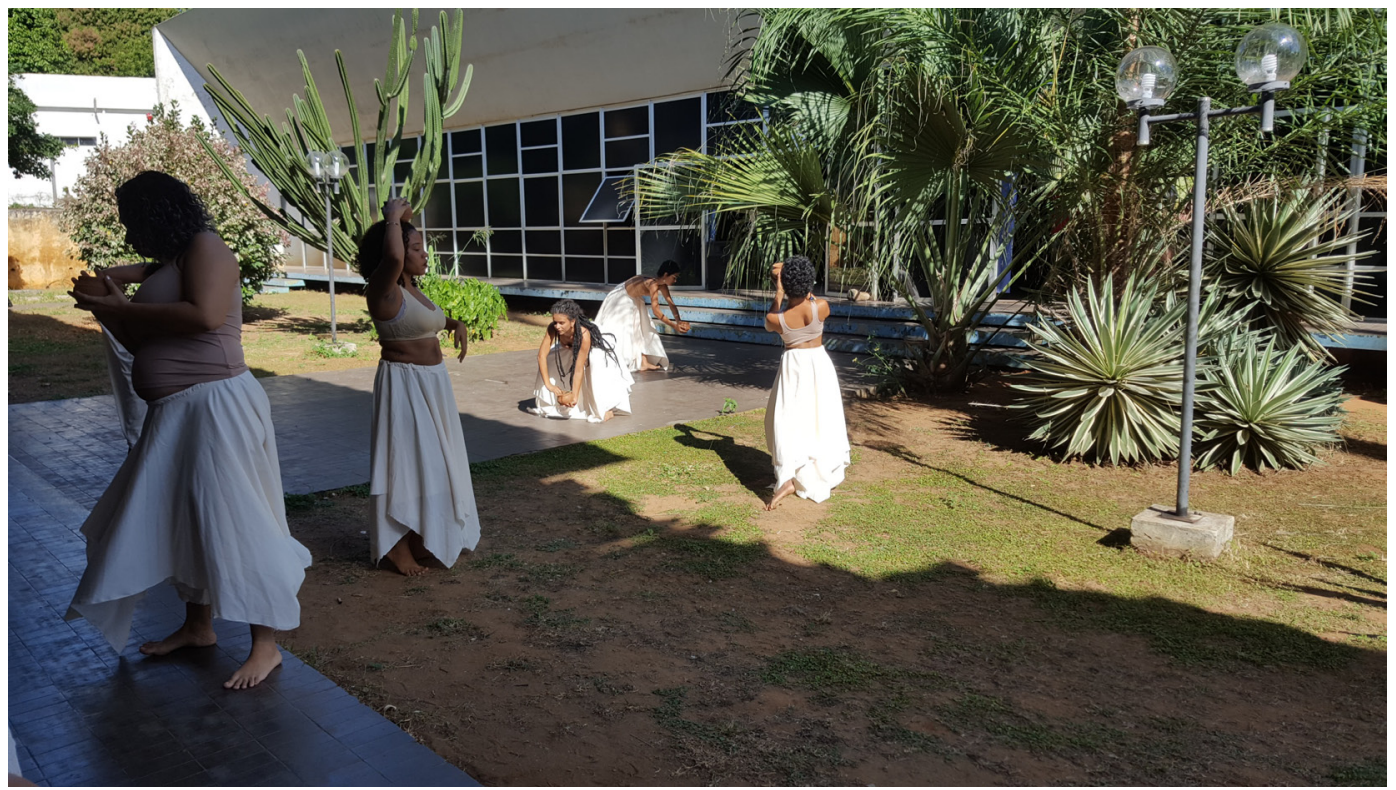

Figura 1. Danza de mujeres en la inauguración del II Seminário Arte/Gênero/Ensino

La realidad brasileña en materia educativa es como mínimo conflictiva, debido a la intromisión del actual gobierno conservador, que está generando una auténtica presión, especialmente sobre el profesorado de humanidades y materias artísticas. De esta cuestión apremiante y de muchos otros aspectos vinculados a la educación artística se habló durante la semana del Seminario, en un ambiente creativo, con una gran generosidad por parte de la organización, y contando con la participación de jóvenes estudiantes y artistas procedentes de distintos estados de Brasil. En la entrevista se cruzan las opiniones de tres profesionales muy implicados en la realidad de la educación en artes brasileña. Una gran oportunidad para escuchar tres voces especialmente relevantes en el panorama de la reflexión sobre género, feminismo y diversidad LGTB dentro del marco de la enseñanza de las artes.

\section{Ricard Huerta: ¿Cómo se vive actualmente la educación artística en Brasil?}

Everson Melquiades: Desde 1996, con la promulgación de la Ley de Directrices y Bases de Educación Nacional número 9.394, la enseñanza de las artes en Brasil ha logrado avances significativos. Entre estos podemos destacar la enseñanza obligatoria de los lenguajes del teatro, la danza, las artes visuales y la música, en todos los niveles de Educación Básica (que va de Educación Infantil hasta Secundaria), la enseñanza obligatoria del arte y la cultura africana, afrobrasileña y de los pueblos originarios de Brasil, así como la obligatoriedad de la enseñanza del arte en los cursos de grado de docentes que trabajan en los primeros años de escolaridad. De todos modos, es importante aclarar que estos y otros logros son el resultado de la lucha de los arte/ educadores brasileños a través de su trabajo en asociaciones locales, nacionales e internacionales en el campo del arte, la educación, y la educación artística, como la Associação Nordestina de Arte/Educadores (ANARTE), la Federação de Arte/ 
Educadores do Brasil (FAEB), la Associação Nacional de Pesquisa e Pós-Graduação em Educação (ANPED), la Associação Brasileira de Pesquisa e Pós-Graduação em Artes Cênicas (ABRACE), el Consejo Latinoamericano de Educción por el Arte (CLEA), entre otros. Sin embargo, en la actualidad, necesitamos una vigilancia ontológica y epistemológica de los arte/educadores para que no tengamos retrocesos en las políticas públicas de enseñanza del arte, en vista del gobierno ultrafascista instalado en Brasil por las fuerzas conservadoras.

Fabio Rodrigues: Actualmente en Brasil, la educación artística se ha consolidado, tanto en lo relativo a la formación inicial de maestros y maestras, como en la formación impartida en los programas de máster y doctorado. Hoy, las universidades ofrecen títulos universitarios en las cuatro áreas (artes visuales, danza, música y teatro) como maestrías y doctorados. Destaco el Programa de Mestrado Nacional em Artes para Professoras e Professores da Educação Básica (ProfArtes), porque este programa de la Coordinación de Perfeccionamiento del Personal de Educación Superior (CAPES), permite a los maestros y maestras del Componente Curricular Arte que puedan incorporarse al Máster para una formación orientada a la investigación sobre prácticas docentes en la enseñanza del arte, iniciando experiencias cualitativas de los procesos de enseñanza y aprendizaje de las artes, así como metodologías y enfoques innovadores de enseñanza.

Vitória Amaral: Educación artística es un término rechazado en Brasil porque apunta a un momento político dictatorial, que influyó en las leyes educativas del país. Este período ocurrió entre 1971 y 1996 con sendas leyes de Directrices y Bases, en el que la enseñanza de las Artes era polivalente (formación de docentes en artes visuales, danza, música y teatro en dos años), por tanto una educación superficial sin profundizar. Después de este período, tenemos un título universitario específico en Artes, lo cual permite formar maestros de Artes Visuales, Danza, Música y Teatro. En la mayoría de las universidades de Brasil, esta formación está bien articulada y permite una formación crítica, atendiendo a los cambios sociales y culturales. A partir de este movimiento, que trae otra mirada arte/educadora, comenzamos a introducir estudios sobre diversidad y género, con un currículum que selecciona mujeres, mujeres negras y artistas LGTB. Todos los avances provienen de las luchas de la Federación de Arte/Educadores de Brasil (FAEB), fundada en la década de 1980, con Ana Mae Barbosa, la mentora de todos nosotros. Sin embargo, a menudo no existe una política pública en educación, y cada secretario de educación que asume el cargo a nivel municipal, estatal o federal, sigue las políticas de alcaldes, gobernadores y presidentes, incumpliendo las leyes al no contratar especialistas. En la formación de profesorado de artes visuales en la UFPE, desde el comienzo del curso respetamos la individualidad de cada estudiante y toda la formación se basa en las inquietudes del alumnado, ya sea sobre género, identidad, sexualidad, poder, religión o cualquier cosa que provenga del propio estudiantado. Ingresan a la universidad personas que se sienten reprimidas, aisladas y discriminadas $(50 \%$ a través de cuotas para negras y negros, y escuela pública, y $70 \%$ con ingresos 
familiares por debajo de 3 salarios mínimos). Salen de la universidad con una comprensión clara de su identidad, con la voluntad de ir al aula para ampliar estas narrativas con otras mujeres, negras y/o LGTB.

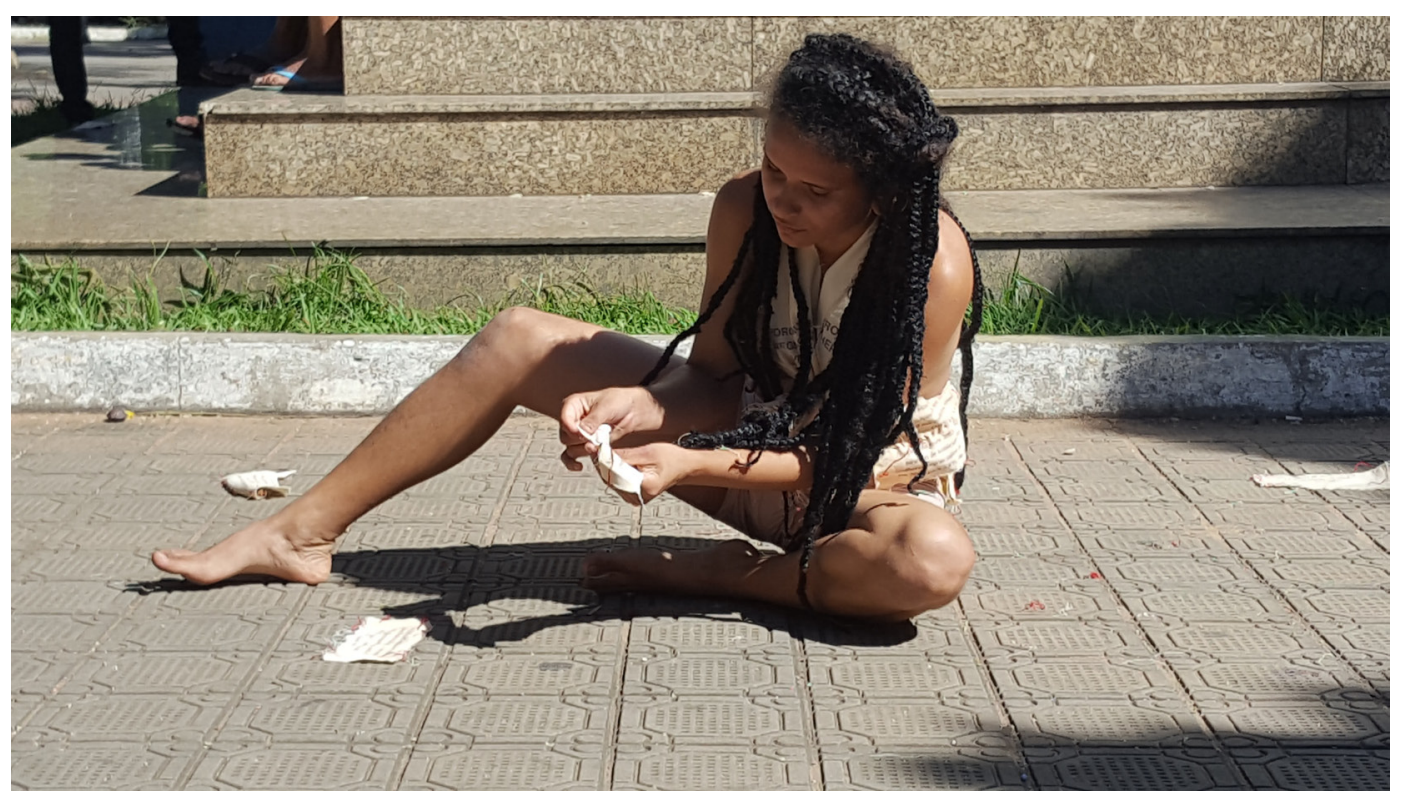

Figura 2. Performance Tálamo de Maria Macêdo en el Seminário Arte/Gênero/Ensino

\section{RH: ¿Qué importancia tiene revisar la historia de la educación artística en el momento presente?}

FR: La historia de la enseñanza y el aprendizaje del arte en el contexto brasileño ha sido revisada tanto en relación con los enfoques didáctico-pedagógicos, como con los vínculos con las prácticas artísticas de artistas que eran invisibles para la historia del arte y, en consecuencia, para la historia de la enseñanza de arte. Las prácticas artísticas de las mujeres, la población negra, la población LGTB, así como los pueblos indígenas que han sido silenciados, están impulsando un cambio hacia la inserción de estas prácticas dentro del aula. Los estudiantes reclaman otros enfoques más cercanos a sus experiencias diarias, comunitarias y regionales en diálogo con otros contextos culturales y otras formas de entender la singularidad y diversidad de las personas. El aumento de la violencia contra las mujeres, la población negra, la población LGTB y las poblaciones indígenas, reforzado por el discurso de odio promovido por el actual gobierno brasileño, ha afectado al arte en general. Y los ataques al arte también son ataques a su enseñanza y aprendizaje. Combatir el fascismo que se vive en Brasil pasa por una revisión de todas las bases conceptuales, metodológicas y didácticas sobre el arte y sus procesos de enseñanza y aprendizaje.

VA: Con la actual política en Brasil, la importancia de contar la historia del arte/ educación es enorme y urgente, porque la represión y la violencia son excesivas, especialmente en relación con las mujeres, los negros, los indígenas y los LGTB. 
Necesitamos fortalecer estos grupos y la educación es la mejor manera de hacerlo, tal vez la única forma en que podemos abrir los ojos para estar al tanto de las violaciones de los derechos humanos.

EM: Con el avance de las fuerzas conservadoras y ultrafascistas en todo el mundo, se necesita una revisión urgente de la historia del arte y la educación artística. En Brasil, un ejemplo de este esfuerzo se puede encontrar en el desempeño de profesoras como Ana Mae Barbosa y Madalena Zaccara. En 2017, Madalena lanzó el libro De Sinhá prendada a Artista Visual: Os Caminhos da Mulher Artista em Pernambuco, y este año, Ana Mae ha promovido el libro Mulheres não devem ficar em silêncio: Arte, Design, Educação. Ambas hacen una revisión crítica de la historia de las artes visuales y la educación artística desde el punto de vista de las mujeres que han sido silenciadas por la historia producida por una sociedad machista, occidental, de corte norteamericano, blanco y europeo.

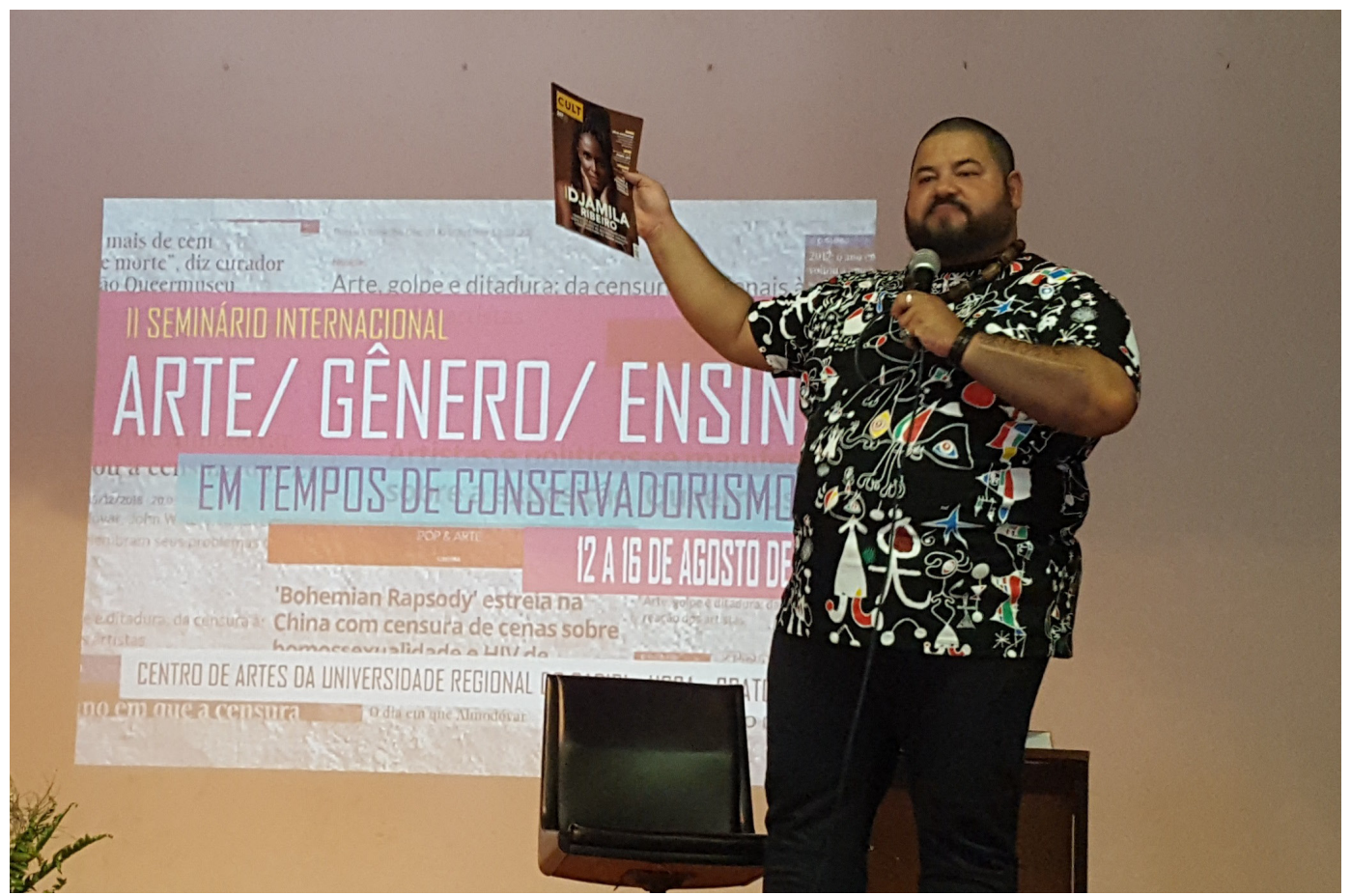

Figura 3. Ponencia de Everson Melquíades en el Seminário Arte/Gênero/Ensino.

\section{RH: ¿Se deben abordar en educación artística las cuestiones de género, feminismos y diversidad sexual?}

VA: Sí, siempre, dando visibilidad a las mujeres, personas LGTB, asumiendo que las teorías feministas apuntan hacia una sociedad más igualitaria, horizontal, más colaborativa y democrática. Las propuestas feministas rechazan la dicotomía, sea la que sea, y se centran en aspectos que en otros momentos fueron considerados trivialidades, valorando las pequeñas acciones de las mujeres, como por ejemplo el bordado. Se trata de reflexiones diseñadas por mujeres pero no solo para mujeres, comenzando con la experiencia misma, incorporando críticas al racismo y al 
heterosexismo, tratando de dar visibilidad a artistas mujeres, y siendo conscientes de los estereotipos de condescendencia, objetivación, prejuicio contra el género, la raza, la edad, la capacidad intelectual, la sexualidad, la clase, el origen étnico y otras diversidades humanas. Conviene hacer una investigación más cualitativa desde la investigación y comprensión social, cultural, económica y política.

FR: ¡ $\mathrm{Si}$, claro! El arte como conocimiento humano no debe estudiarse disociado del género, el feminismo y la diversidad sexual. Hoy estamos experimentando vivencias estéticas de la relación entre pensar y crear desde los márgenes y las marginalidades. En este sentido, nos encontramos con prácticas artísticas que problematizan cuestiones de género y postgénero. Tales problematizaciones encuentran en diferentes enfoques feministas contribuciones muy importantes para comprender los lugares de pertenencia de mujeres y hombres, de disidencia de género, y de la comprensión del género como una construcción social y cultural. Al mismo tiempo, observamos que en las prácticas artísticas actuales también se aborda y problematiza la diversidad sexual. Hay un número creciente de activistas LGTB que están experimentando con modos de producción para dar visibilidad a los derechos de esta población tanto en lo referido a lo ya logrado como a lo que queda por conquistar.

EM: Nadie nace homofóbico, xenófobo o racista. Aprendemos desde la infancia, a partir de diferentes procesos de socialización, en espacios como la escuela, la familia, la comunidad, a ser homofóbicos, xenófobos y racistas. Por tanto, es urgente que trabajemos desde la infancia en una educación para las relaciones de género y la diferencia sexual. En esta tarea, el arte y la educación artística tienen un papel primordial en la formación de las nuevas generaciones, ya que permiten una reflexión crítica y radical sobre la vida y el vivir.

\section{RH: ¿Cómo podemos incorporar las temáticas sobre género y diversidad a nuestro trabajo docente universitario?}

EM: Existen muchas formas de incluir el género y las diferencias de género en nuestra práctica docente en la educación superior, que van desde la creación de procesos de investigación, enseñanza y difusión sobre este tema hasta la elección de artistas para explicar en nuestras clases. Sin embargo, también es importante el reconocimiento y la asunción de mi identidad de género con el alumnado, además de presentar una postura y posicionamiento que evite cualquier forma de discriminación. Esto significa que no es suficiente enseñar a nuestros estudiantes contenidos conceptuales y procedimentales sobre estos temas. Como nos dice el gran educador Paulo Freire en el libro Pedagogía de la autonomía, educar requiere cosificar las palabras con el ejemplo. Por ello, a través de mi presencia auténtica, mi alumnado también aprende actitudes. 
VA: Lo primero que debemos hacer es cambiar nuestro plan de estudios agregando más mujeres, artistas LGTB, negras y negros, indígenas, locales y regionales. A partir de aquí, llevar a las aulas la discusión basada en estos artistas, considerando las historias de vida de los estudiantes. Uno de los caminos para una transformación docente e inclusiva son las teorías feministas que rompen con el androcentrismo, trayendo consigo un discurso más plural, más horizontal, pero democrático y cíclico. Debemos estar atentas a las referencias artísticas y bibliográficas. Nunca dejar de hablar de artistas extranjeros, pero también incluyendo en nuestras aulas a artistas que están cerca de nuestro alumnado, así como su propia producción.

FR: Sostengo que el profesorado selecciona imágenes de arte y cultura visual para su lectura, contextualización e interpretación, incorporando artistas mujeres, artistas negras, artistas negros, artistas LGTB y artistas indígenas. La inclusión de esta producción artística o cultura visual colabora tanto para reducir el silencio y lo sufrido por estos artistas, como para pensar en nosotros mismos como sujetos de nuestro tiempo, comprometidos con el escenario progresista, que se niegan a mantener nuestros contextos culturales alimentados por prejuicios, la discriminación, el silenciamiento, la eliminación, el conservadurismo, la heteronormatividad, elsexismo, y el machismo que alimentan la violencia de género, la violencia contra la población LGTB, la violencia contra la población negra y la violencia contra los indígenas o cualquier otra población que no se ajuste a los criterios defendidos por los fascistas.

\section{RH: ¿Qué referentes (autores, autoras, trabajos) deberíamos tener en cuenta?}

VA: Tenemos que acercar a nuestros estudiantes a artistas contemporáneos. Sus propias obras deben ser valoradas, así como las de los artistas de sus comunidades, mujeres, artistas negros, indígenas y LGTB, que nunca están en los libros de historia del arte. Apreciar lo que alguna vez se consideró "trabajo de mujeres", que se llama artesanía porque no se encuentran en los grandes museos. En Brasil, hay omisión de artistas latinoamericanos. Para tener una sociedad más justa, debemos desviar la atención habitual hacia los artistas europeos, hombres, blancos y cis. En cuanto a la autoría de libros teóricos, procurar leer más mujeres, mujeres negras, indígenas y LGTB porque es otra mirada hacia el mundo. Como dice Marián López-Fdez. Cao: "la historia del arte no debe ser la historia del genio individual, occidental, masculino y burgués medio, sino la historia de la creatividad a través de imágenes, superando individualidades, orígenes geográficos y económicos, para mostrar nuevas formas de entender y expresar el mundo".

FR: Creo que en cada contexto cultural hay innumerables contribuciones para comprender los problemas que rodean el arte y sus procesos de enseñanza y aprendizaje desde una perspectiva progresista. Mis lecturas son de autoras y autores que se encuentran en la desobediencia epistémica como Mignolo, Quijano, CastroGómez, Butler, Frantz Fanon, Rocío Polania, Ana Mae Barbosa, Ricard Huerta, Bruno Bimbi, João Silvério Trevisan, Paulo Freire, Daniel Borrillo entre otros 


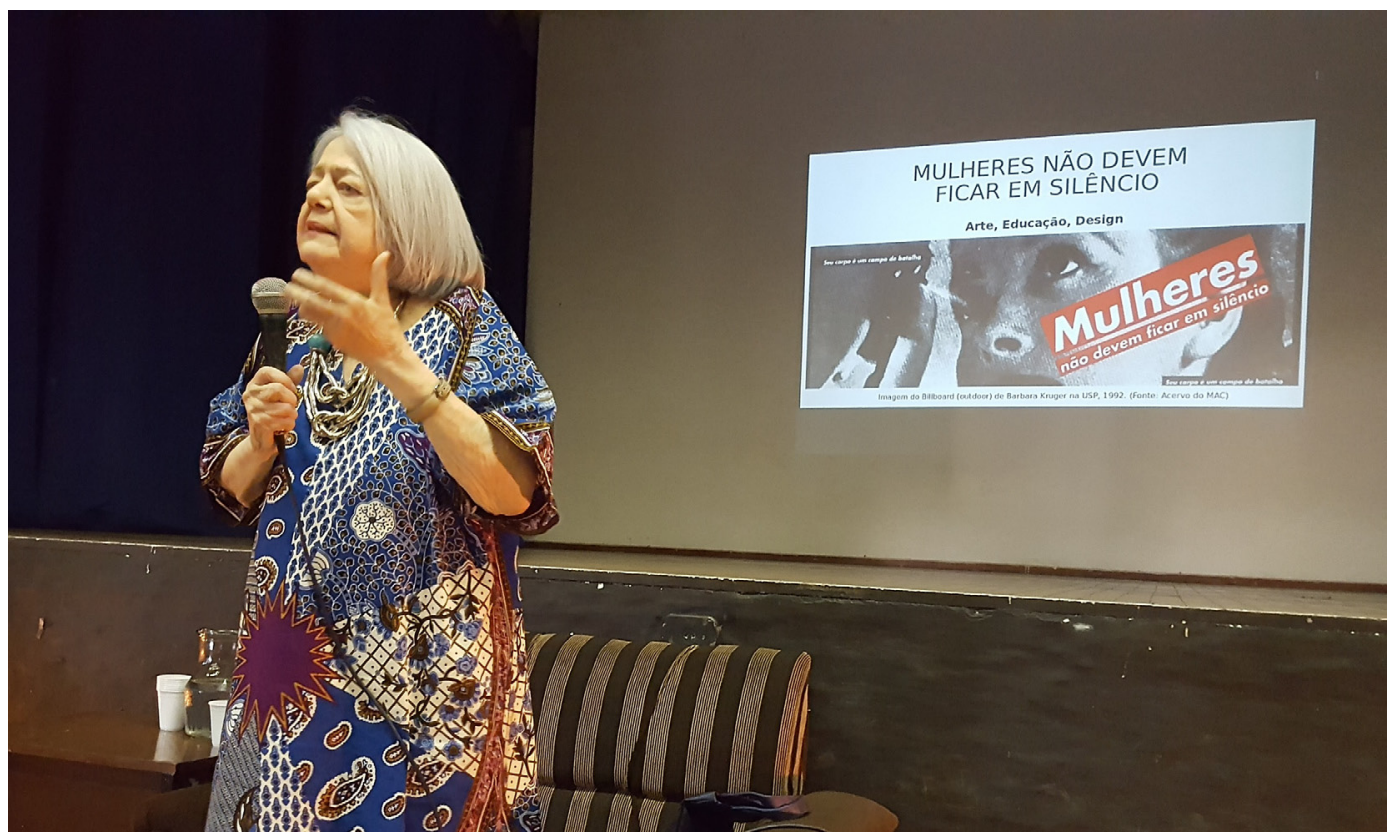

Figura 4. Intervención de Ana Mae Barbosa en el Seminário Arte/Gênero/Ensino

EM: En el campo arte/educativo en Brasil, las grandes pioneras en temas de género y diferencia sexual son las profesoras Ana Mae Barbosa, de la Universidade de São Paulo (USP) e Ivone Mendes Richter, de la Universidad Federal de Santa María (UFSM). También destacamos los nombres de Luciana Gruppelli Loponte, de la Universidad Federal de Rio Grande do Sul (UFRGS), Fábio Rodrigues, de la Universidad Regional do Cariri (URCA), Belidson Dias, de la Universidad de Brasilia (UNB), Afonso Medeiros, de la Universidad Federal do Pará, así como Fernando Azevedo, Luciana Borre y Vitória Amaral, estos tres últimos, de la Universidade Federal de Pernambuco. A nivel internacional, los profesores de españoles Ricard Huerta, de la Universidad de Valencia y Marian López FdezCao, de la Universidad Complutense de Madrid, se han convertido en referencias internacionales sobre estas temáticas.

\section{RH: ¿Qué otros aspectos problemáticos del panorama actual merece la pena valorar en la formación de artistas y educadores?}

FR: Entender la educación como una práctica de libertad, como Paulo Freire ya nos enseñó. En cualquier contexto cultural en el que existan desigualdades, opresión, discriminación, pobreza y hambre, nuestro proceso de humanización está condenado al fracaso.

VA: Hay que valorar siempre lo que proviene del alumnado. ¿Cómo podemos conectar sus producciones con las de otros artistas? Debemos ser plurales. Para Ana Mae Barbosa el feminismo ha traído al arte preguntas que siguen siendo vitales actualmente, como las definiciones de subjetividades, agendas políticas personales e institucionales, estrategias del cuerpo femenino y narrativas múltiples, la relación 
entre lo público y lo privado, y la relación entre arte y artesanía. Las subjetividades deben estar en el centro de las discusiones, el arte es necesario para cuidarnos a nosotros mismos, a nuestros cuerpos y al mundo en el que operamos. Otra cosa que es fundamental para mí es comprender el imaginario en el que estamos insertos, entendiendo que los mitos organizan nuestra cultura. Podemos interferir con este ciclo mítico, que es social, político y económico. Según Gilbert Durand, lo imaginario es un museo de imágenes vividas, pasadas, presentes y futuras. Debemos prestar atención a estas imágenes cotidianas para comprender quiénes somos.

EM: Insisto tanto en cuestiones de género y diferencia sexual como en cuestiones étnicas y raciales. Con los cambios en la legislación y la implementación de políticas públicas en los últimos 20 años, pensábamos que ya habíamos avanzado en estos temas dese el punto de vista social. Sin embargo, en la coyuntura política brasileña actual, artistas y educadores están siendo perseguidos por las fuerzas conservadoras y ultrafascistas que han calificado peyorativamente estos temas como "Ideología de género" y han promovido proyectos de ley como "La escuela sin partido", que constituye un revés político en el campo de la educación.

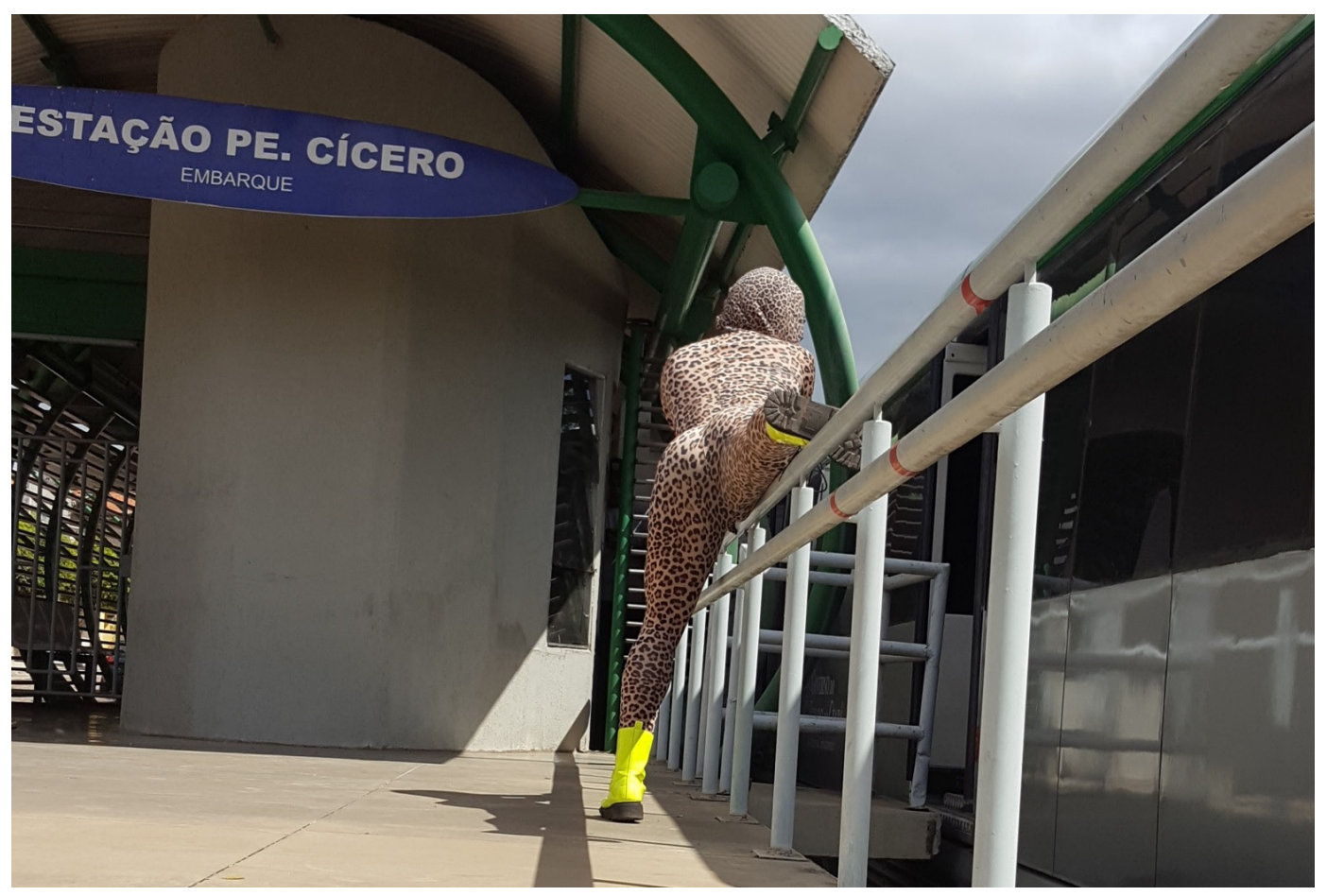

Figura 5. Performance Super Sentai de Rafael Bqueer. Seminário Arte/Gênero/Ensino

\section{RH: ¿Qué países o tendencias están apostando más por la educación en género y diversidad desde el arte y la educación?}

EM: Esta es una pregunta difícil de responder, ya que mis lecturas y relaciones académicas se han limitado a los países de habla latina de los países de América, Europa, África y Asia. En este círculo, he encontrado una mayor preocupación en países como Brasil y España. 
FR: No puedo señalar ningún país, porque entiendo que la existencia de violencia de género y la lgtbfobia existe incluso en países que han avanzado en términos de leyes, pero en el contexto cultural continúan existiendo. Una educación para combatir la violencia de género, racial y de orientación sexual requiere el compromiso de mujeres y hombres progresistas que, en su docencia, se ponen a disposición para la lucha diaria contra el fascismo, y se repiensan como mujeres y hombres que viven en contextos interculturales. Asumen la necesidad de combatir el capitalismo y sus estrategias de dominación. Como nos dice Paulo Freire: "El futuro pertenece a la gente y no a los imperios".

VA: En términos de arte/educación, Brasil está muy por delante en las discusiones a todos los niveles. Estamos iniciando la investigación sobre género y diversidad en arte/educación, pero lo cierto es que esto aún no existe en muchos otros países latinoamericanos. Tenemos el privilegio de contar con una intelectual y teórica del nivel de Ana Mae Barbosa, que siempre ha luchado políticamente por preservar el arte/educación en Brasil. Para reflexionar sobre género y diversidad estudiamos teóricos de Brasil, Argentina, México, España, Ghana y otros países africanos, Irak, Estados Unidos, Francia, Inglaterra. Tenemos que respetar cada cultura en sus diferencias. Debemos leer a quienes hablan sobre género, negritud, racismo, LGTB y llevar a nuestras aulas las producciones de mujeres, negros, artistas indígenas para reflexionar sobre ello.

\section{RH: ¿Deberíamos implicar a museos y otras entidades o instituciones en nuestras investigaciones?}

EM: Creo que la investigación relacionada con el arte/educación y las cuestiones de género y diferencia sexual no deben limitarse al entorno escolar. Por el contrario, estos temas también deberían incorporarse al ámbito de la educación no formal, desarrollada por museos y diferentes instituciones culturales, como el Museo de la Diversidad Sexual en Brasil y Museari en España.

VA: Sí, por supuesto, tenemos que acercar más a las instituciones que no tienen una formación contemporánea, contaminada con el racismo y los prejuicios de género, y generar asociaciones para dar a conocer las obras de arte de mujeres negras, periféricas, lesbianas, parejas homosexuales y todos aquellos que están fuera del centro hegemónico del arte. ¡Dar visibilidad a todxs!

FR: Sostengo que cualquier proceso de enseñanza y aprendizaje del arte debe involucrar museos, centros culturales, galerías, y también espacios públicos como plazas y calles. Por supuesto también espacios alternativos como comunidades, periferias, quilombos, asentamientos, lugares de lo sagrado, es decir, en todas partes donde tenga lugar la experiencia estética. 


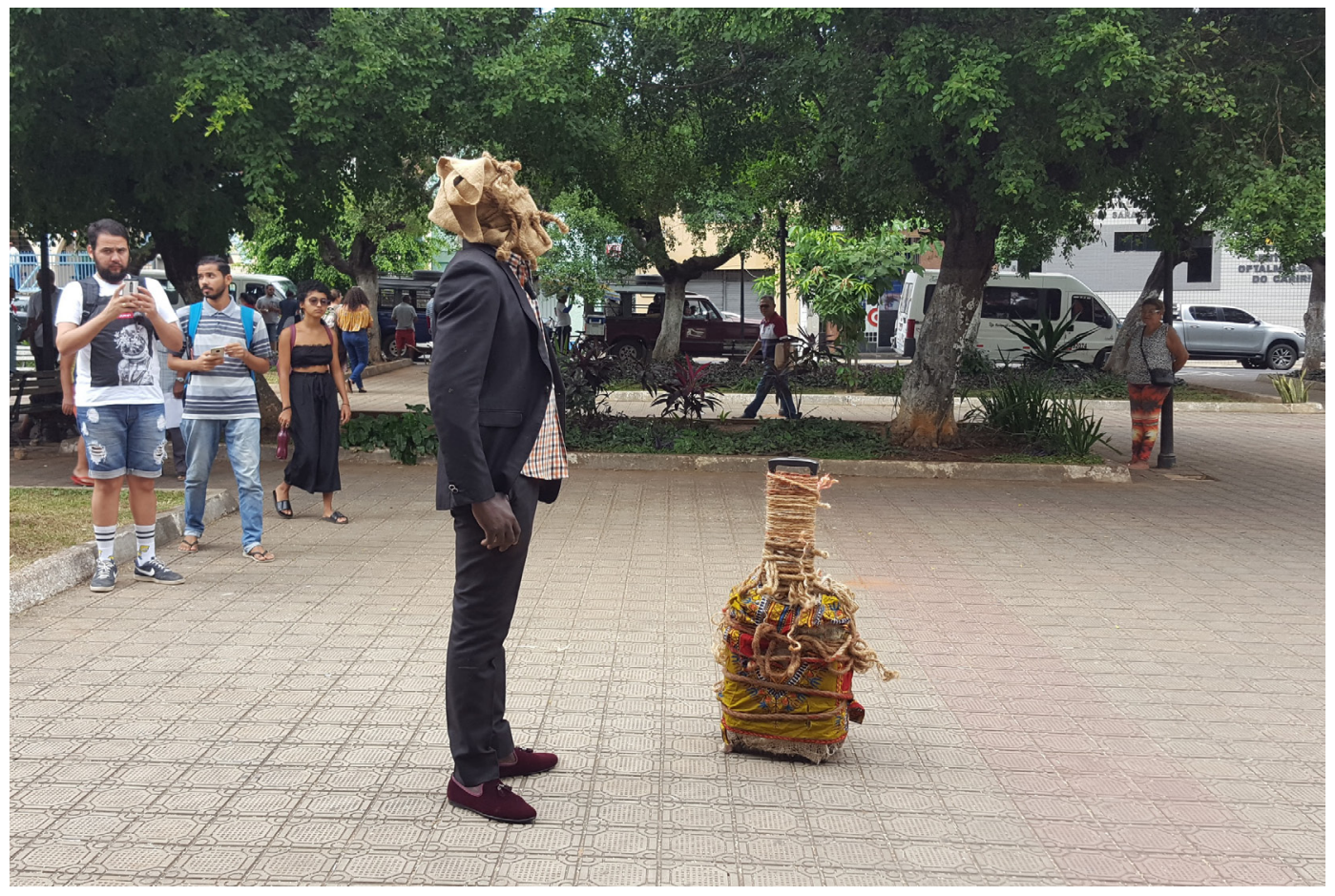

Figura 6. Performance Bagagem de Shambuyi Wetu en el Seminário Arte/Gênero/Ensino

\section{RH: En Brasil existe la formación universitaria de arte/educadores para todos los niveles educativos, pero en España no. A partir de esta diferencia, ¿podemos encontrar puntos de encuentro?}

VA: Creo que los puntos de encuentro son con los educadores y educadoras que trabajan en estas perspectivas, saliendo de la mirada del colonizador, del arte hegemónico, de los grupos sociales privilegiados. Debemos hacer convenios, intercambios de profesorado, estudiantes y artistas.

FR: Sí, en cada contexto cultural, la formación inicial y continua de los docentes sucede de acuerdo con las condiciones concretas de cada uno. Aunque España no ofrece la misma capacitación que Brasil, sabemos que la formación ofrecida allí es de extrema calidad.

EM: En los últimos 20 años, Brasil ha dado un salto altamente cualitativo y cuantitativo en el área de formación docente para la enseñanza de las artes, ya sea para trabajar en los primeros de escolarización o en últimos años, habiendo renovado los sistemas de formación continua para maestros y maestras en activo. Uno de los elementos comunes entre Brasil y España es la preocupación de las Facultades de Educación en la formación para la enseñanza del arte de los docentes que actuarán con la infancia. 


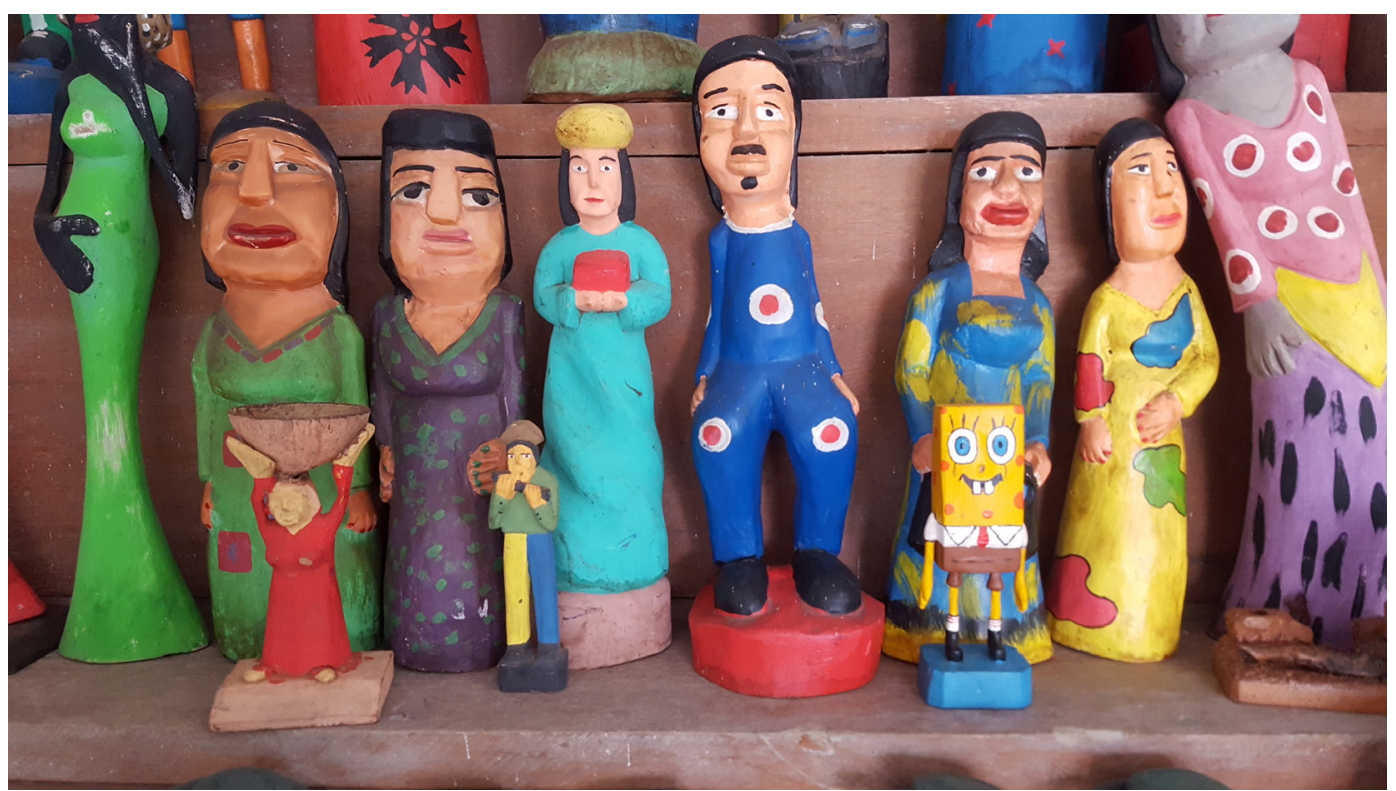

Figura 7. Artesanía popular de la región del Cariri.

\section{RH: ¿Qué mensaje podemos transmitir a las generaciones más jóvenes?}

FR: Aprender a desaprender como condición para luchar contra el fascismo y superar el conservadurismo que se está apoderando de nuestros contextos culturales.

VA: El arte/educación es el camino para descubrirse a sí mismo y al otro. Es creando y produciendo arte cuando nos damos cuenta de quiénes somos, sabiendo cómo debemos vivir mejor. El arte y su creación toman las imágenes de nuestros amores, de nuestras ansiedades, del interior del alma. Tenemos que crear para hacernos visibles, crear para contar nuestras historias, crear para mostrar nuestra etnia, crear para reconstruir la vida, crear para producir con las manos, con los pies, con el cuerpo, para romper las barreras de los prejuicios y la opresión. El arte/educación propone una sociedad más justa, igualitaria y democrática a través de la producción, la lectura y la contextualización del arte.

EM: Somos de una generación que tuvo muchas dificultades para reconocer y asumir la propia identidad sexual, incluso socialmente. Pero somos una generación que luchó duro para que hoy todo sea diferente. Creo que tenemos muy poco que enseñar a estas nuevas generaciones. A lo sumo, tenemos algo que intercambiar, dialogar y aprender de ellos sobre cuestiones de género y diferencia sexual. Esto se debe a que son pragmáticos, y nosotros todavía somos propedéuticos. 